This item was submitted to Loughborough's Research Repository by the author.

Items in Figshare are protected by copyright, with all rights reserved, unless otherwise indicated.

\title{
Humid heat and climate change
}

PLEASE CITE THE PUBLISHED VERSION

https://doi.org/10.1177/0309133318776490

PUBLISHER

SAGE $\odot$ The Author

VERSION

AM (Accepted Manuscript)

\section{PUBLISHER STATEMENT}

This work is made available according to the conditions of the Creative Commons Attribution-NonCommercialNoDerivatives 4.0 International (CC BY-NC-ND 4.0) licence. Full details of this licence are available at: https://creativecommons.org/licenses/by-nc-nd/4.0/

\section{LICENCE}

CC BY-NC-ND 4.0

\section{REPOSITORY RECORD}

Matthews, Tom K.R.. 2019. "Humid Heat and Climate Change". figshare. https://hdl.handle.net/2134/33963. 


\begin{abstract}
Extreme heat events cause significant societal impacts, prompting much concern and research about possible changes to their frequency and intensity as the climate warms. However, to date, extremes in air temperature have been emphasised at the expense of 'heat-humidity' indices, measures which incorporate the effect of atmospheric latent heat content on heat stress and provide a more complete picture of the thermal environment for human thermoregulation. This progress report restores balance by reviewing recent developments in the understanding of how heat-humidity indices have changed, and may continue to, as the climate warms further. The literature indicates that a concurrent rise in temperature and absolute humidity has already increased the frequency of potentially deadly conditions, and has reduced labour potential worldwide. More serious consequences may result if mitigation efforts are unsuccessful. The energetic basis of a heat-humidity perspective has permitted researchers to identify, for example, that by the end of the century, substantial parts of the Earth's surface may be too hot and humid for human thermoregulation. Such consequences are avoided for less pessimistic scenarios of climate warming, but the societal impacts may still be very severe, as densely-populated low-latitude environments emerge as particularly at risk when a humid heat perspective is adopted. Counter to air temperature, changes in mean heat-humidity indices are actually amongst the largest worldwide at lower latitudes, where only small increases in the mean may be required to substantially enhance the frequency of dangerous conditions. The report concludes by outlining areas requiring improved process understanding, and it highlights the urgent role for societal adaptation if the worst impacts from rising humid heat are to be avoided.
\end{abstract}

\title{
I Introduction
}

Global air temperatures have risen since the Industrial Revolution, driving more frequent and intense extreme heat events (Fischer and Knutti, 2015; Seneviratne et al., 2014). This trend is projected to persist as global mean air temperatures continue to climb (Sillmann et al., 2013), which is of concern due to the impacts of extreme heat on human health (Hajat and Kosatky, 2010) and economic productivity (Kjellstrom et al., 2016).

The occurrence of heat extremes in the context of climate change has accordingly received much attention, and comprehensive reviews addressing physical processes, trends, future projections, and societal impacts have been compiled (Horton et al., 2016; Kjellstrom et al., 2016; Sheridan and Allen, 2015). However, from a process perspective, the focus has been primarily on the sensible heat content of the air, through analysis of the dry bulb temperature (hereafter simply 'air temperature'). Far less attention has been afforded to combined heathumidity extremes. This is addressed in the current Progress Report, because integrating humidity into assessments of extreme heat permits more complete characterisation of the environmental conditions influencing human heat exchange. In what follows, the energetic basis underpinning this assertion is first provided (Section II), before recent research on observed changes in heat-humidity variables is summarised (Section III). Future projections for these quantities are then assessed in Section IV, and the implications of these findings in the context of societal impacts are discussed in Section V. Finally, a synthesis and future outlook is provided in Section VI.

\section{Energetics and Heat-Humidity Indicators}


A comprehensive exposition of the physics of heat exchange between humans and their environment is provided by Gagge and Gonzalez (2010), whilst Davis et al. (2016) focus specifically on the role of atmospheric humidity. Here, these fundamentals are synthesised to underline the importance of integrating humidity into assessments of heat extremes in a changing climate.

The energy balance of the human body can be written (e.g. Oke, 2009):

$q_{H}+q_{L}+q_{G}+q_{S}+q_{L W}+\Delta q=0 \quad$ Eq. 1

where $q_{H}$ and $q_{L}$ are the sensible and latent (turbulent) heat fluxes; $q_{G}$ is the conductive heat flux; $q_{S}$ and $q_{L}$ are the net shortwave and longwave (radiative) heat fluxes; and $\Delta q$ is the heat storage term. If overheating is to be avoided, $\Delta q$ should balance the body's rate of metabolic heat production.

The atmospheric humidity influences $q_{L}$, which in turn plays a critical role in human thermoregulation. To illustrate, consider energy transfer from a $1 \mathrm{~m}^{2}$ wet (sweat-saturated) patch of skin. The sensible heat flux is a function of the temperature gradient between the ambient air $\left(T_{A} ; \mathrm{K}\right)$ and skin $\left(T_{S K} ; \mathrm{K}\right)$ temperatures, and the convective heat transfer coefficient $\left(h_{c} ; \mathrm{W} \mathrm{m}{ }^{-2} \mathrm{~K}^{-1}\right)$ :

$q_{H}=h_{c}\left(T_{A}-T_{S K}\right) \quad$ Eq. 2

Analogously, the latent heat flux is given by the difference in vapour pressure between the ambient air $\left(P_{A} ; \mathrm{Pa}\right)$ and immediately above the saturated skin surface $\left(P_{S K} ; \mathrm{Pa}\right)$ :

$q_{L}=h_{m}\left(P_{A}-P_{S K}\right) \quad$ Eq.3

Making use of the Lewis Relation $\left(L R ; \mathrm{K} \mathrm{Pa}^{-1}\right)$, which provides the ratio $h_{m} / h_{c}$, equations 2 and 3 can be combined:

$q_{H}+q_{L}=h_{c}\left[\left(T_{A}+L R \cdot P_{A}\right)-\left(T_{S K}+L R \cdot P_{S K}\right)\right] \quad$ Eq. 4

For a Lewis Number (ratio of Schmidt to Pradtl numbers) equal to unity, the term $T_{A}+$ $L R \cdot P_{A}$ corresponds directly to the equivalent temperature defined in the climatological literature (Fischer and Knutti, 2013), and when multiplied by the specific heat capacity of the air, it is the moist enthalpy, also referred to by others as the heat content and the moist static energy (Peterson et al., 2011; Pielke et al., 2004).

Humans must sustain their core body temperature within a narrow range (about $\pm 1.5^{\circ} \mathrm{C}$ ) of $36.8^{\circ} \mathrm{C}$ to maintain normal metabolic and organ functioning (Hanna and Tait, 2015). If core temperature rises beyond this, death may result via numerous physiological pathways (see Mora et al., 2017a). Heat produced internally must therefore be dissipated to the environment if negative health outcomes are to be avoided (cf. Equation 1), which in turn requires a skin temperature of around $35^{\circ} \mathrm{C}$ to ensure metabolic heat is conducted from the core (Sherwood and Huber, 2010). This skin temperature can be substituted into Equation 4 to identify a thermodynamic limit beyond which turbulent heat dissipation to the environment is not possible. The hatched area in Fig. 1 highlights this area, which is approximately bounded by wet bulb temperature $\left(T_{W}\right)=T_{S K}=35^{\circ} \mathrm{C}$ (note that it is only approximately bounded because the assumption of a Lewis Number equal to unity has been relaxed; see Gagge and Gonzalez, 
2010, for the parameterization of $L R$ ). The other terms in Equation 1 may also influence the maximum moist enthalpy that can be tolerated. Solar radiation would increase the heat load, whilst the longwave term may be heat sink or source, depending on the geometry, temperature and emissivity of the surroundings. For completeness, the orange curve in Fig. 1 provides an optimistic assessment of the upper limit of temperature and relative humidity that may be tolerated indoors if these fluxes are considered (assuming no solar radiation, modest air motion, uniform surroundings with surfaces temperature equal to air temperature, and ignoring $q_{G}$; see Fig. 1. caption).

Although not directly observed, it is straightforward to calculate moist enthalpy $(Q)$ from common meteorological quantities:

$Q=Q_{h}+Q_{l}=c_{p} T+\omega L_{v} \quad$ Eq. 5

where enthalpy and latent heat are denoted by $Q_{h}$ and $Q_{l}$, respectively. The former is a product of air temperature $(T ; \mathrm{K})$ and the specific heat capacity of air $\left(c_{p}\right.$, whilst the latter is a product of the specific humidity ( $\omega$; grams of water vapour per gram of air) and the latent heat of vaporization $\left(L_{v} ; \mathrm{J} \mathrm{kg}^{-1}\right)$.

Fig. 2 illustrates the result from applying Equation 5 to the European Centre for Medium Range Reanalysis ERA5 (available 2010-2016), using $c_{p}=1005 \mathrm{~J} \mathrm{~kg}^{-1} \times(1+0.84 \times r)$ (in which $r$ is the mixing ratio) and the expression of Henderson-Sellers (1984) to parameterize $Q_{l}$. According to these data, moist enthalpy reaches its greatest extent around the Persian Gulf and in South Asia, where contributions from latent heat are particularly enhanced. This pattern is reproduced globally, with Fig. 2D highlighting a greater latent heat partitioning for those places experiencing higher moist enthalpy. Note that the peak temperatures do not generally indicate the periods of maximum moist enthalpy, providing practical illustration of the need to characterise the thermal environment using total energy content, rather than just sensible heat (cf. Pielke et al., 2004).

Sherwood and Huber (2010) concluded that $T_{W}$ has not exceeded $35^{\circ} \mathrm{C}$ over land during the period of modern observations. This is not supported by the more recent, more frequent (hourly), and higher-resolution $\left(\sim 0.28^{\circ} \times 0.28^{\circ}\right)$ ERA5, which shows a maximum instantaneous $T_{W}$ of $35.4^{\circ} \mathrm{C}$ (Fig. 2D), suggesting thermal conditions beyond the physiological limit of humans may have (albeit very rarely) occurred on Earth. Nevertheless, maximum air temperatures exceed $35^{\circ} \mathrm{C}$ far more widely, with ERA5 indicating recent exposure for more than 5.4 billion people (almost $80 \%$ of the 2010 world population; Fig. 3). Above this threshold, heat must be dissipated by sweating, highlighting the importance of latent heat transfer in greatly extending the range of climates tolerable to humans.

In reality, though, determining human heat stress is more complex than alluded to above. Whilst heat dissipation to the environment may theoretically be possible for $T_{W}$ up to $35^{\circ} \mathrm{C}$, it must occur at a rate sufficient to balance internal production if potentially deadly heat storage is to be avoided. Dangerous heat can therefore be apparent for temperature and humidity combinations well before $T_{W}$ exceeds $35^{\circ} \mathrm{C}$. Indeed, the potential for heat stress depends as much on behavioural factors (clothing and metabolic activity levels) as environmental conditions. So called "direct” indices emphasize the latter, typically parameterizing potential heat stress as a function of only air temperature and moisture content (e.g. Roghanchi and Kocsis, 2017). In the climate change research literature, the apparent 
temperature (AT; Steadman, 1979) Humidex (HD; Masterton and Richardson, 1979), Wet Bulb Globe Temperature [WBGT; and in particular it's simplified version: SWBGT (ACSM, 1984; Yaglou and Minard, 1957)] have perhaps been employed most frequently, whilst the comprehensive Universal Thermal Climate Index (UTCI; Bröde et al., 2012; Fiala et al., 2012) was recently proposed as the standard in human biometeorology. Of these, AT, HD and UTCI are scaled to provide a 'feels-like' temperature. All indices are associated with advisory thresholds (Table 1 and Fig. 1) to inform public safety. Once AT is forecast to reach above $41^{\circ} \mathrm{C}$, for example, the US National Weather Service may initiate heat alert procedures (http://www.nws.noaa.gov/om/heat/heat_index.shtml).

Although there is considerable variety in the formulation of the heat indices (see Blazejczyk et al., 2012), the energetic basis of human-atmosphere heat exchange means they all behave similarly to moist enthalpy, particularly for combinations of high temperature and humidity (as evidenced by the nearly coincident isolines in Fig. 4). The discrepancy for AT and UTCI for lower air temperature and humidity combinations reflects the more sophisticated energybalance origins of these indices; for example their inclusion of the cooling effect from reducing clothing extent (Fiala et al., 2012; Steadman, 1979). Because of this similarity, moist enthalpy/equivalent temperature are generally included in the aggregate term 'heathumidity indices' hereafter.

Consideration of the physics of heat exchange in the context of climates encountered by society has underlined the importance of latent heat transfer in human thermoregulation. There is hence a strong precedent, adopted by this review, for assessing climate change and heat stress using these combined heat-humidity indices.

\section{Observed changes in heat-humidity indices}

As global mean air temperatures have risen, global mean relative humidity has stayed approximately constant (Dai, 2006; Simmons et al., 2010; Willett et al., 2014), in line with theory and modelling studies (Byrne and O’Gorman, 2016; Held and Soden, 2000; Joshi and Gregory, 2008). Under these conditions, it follows that means in heat-humidity indices may also have risen. Yet, this is not entirely self-evident, as such aggregated statistics may obscure the spatial variation in the joint evolution of temperature and humidity trends (Buzan et al., 2015). Studies explicitly addressing changes in heat-humidity indices have, however, also reported widespread increases in equivalent temperature, WBGT and AT, with the trends in heat-humidity indices generally steeper than in air temperature alone (Fall et al., 2010; Jacobs et al., 2013; Schoof et al., 2015), or achieving a higher signal-noise ratio and thus greater statistical detectability (Knutson and Ploshay, 2016). Rising heat-humidity indices are not universal, though. For example, negative trends attributed to regional drying have been reported for parts of Australia (Hyatt et al., 2010; Peterson et al., 2011).

Other authors have assessed regional changes in the frequency of extreme values in heathumidity indices (Desai and Dhorde, 2017; Grundstein and Dowd, 2011; Kjellstrom et al., 2013; Mekis et al., 2015), and have mainly found significant increases in the number of threshold exceedances over the latter half of the twentieth century. The few global-scale assessments conclude widespread increases in the frequency of potentially dangerous values have occurred (Willett and Sherwood, 2012), which may have decreased labour capacity worldwide (Dunne et al., 2013), and increased the fraction of the land surface exposed to potentially deadly conditions (Mora et al., 2017b). 
Research exploring the processes driving observed extremes in heat-humidity indices has been limited, with studies instead focussing on temperature extremes in the mid-latitudes (e.g. Fischer, 2014; Miralles et al., 2014). However, Wehner et al. (2016) assessed AT during two contrasting heatwaves in Karachi (Pakistan) and Hyderabad (India) during 2015. They highlighted that, due to high humidity, Karachi AT was much greater than the air temperature during the heatwave; in Hyderabad this difference was more muted. Whist adding little process understanding, these findings underscore the need to assess historic heatwaves using heat-humidity indices if their severity is to be characterised accurately.

\section{Projections}

Since the early projections of AT under climate change by Delworth et al. (1999), Fischer and Knutti (2013) have illustrated that climate model projections of such combined indices are more robust than those focusing on humidity or temperature alone. More studies have since followed (see Buzan et al., 2015), but not in great number compared to projections of air temperature (see Horton et al., 2016). However, the limited research to date has been consistent in its conclusions. Changes in mean and extreme values in the heat-humidity indices are generally expected to be larger than for air temperature alone (Delworth et al., 1999; Matthews et al., 2017; Oleson et al., 2015; Zhao et al., 2015), resulting from the additive effect of projected increases in both atmospheric moisture and air temperature (Collins et al., 2013). Projections have also highlighted the tendency for much larger increases in heat-humidity indices than in air temperature for climates that are already warm and humid. This agrees with observed changes, and can be understood through consideration of energy partitioning. Locations with the highest moist enthalpy are characterised by greater partitioning to the latent heat term (Section II); a larger component of the additional heat input from radiative forcing is therefore used to evaporate surface waters than to raise the sensible heat content of the air, meaning that specific humidity rises faster than air temperature (Peterson et al., 2011).

It follows from the above that some of the well-established patterns in warming rates associated with anthropogenic climate change do not apply to heat-humidity indices. For example, under continued anthropogenic climate change, mean air temperatures are anticipated to warm more over land, with greater rates of increase expected for higher northern latitudes (Diffenbaugh and Field, 2013; Sutton et al., 2007). Where global-scale assessments of projected heat-humidity indices have been pursued, however, the literature indicates comparable changes in mean conditions between land and ocean as global mean air temperatures rise (Delworth et al., 1999). This is consistent with the observation that projected changes to equivalent temperature are almost zonally uniform under climate change, with larger increases in the tropics than mid-latitudes (Byrne and O’Gorman, 2013).

Fig. 5 explores this behaviour in more detail, applying Equation 5 to monthly mean model output from 23 climate models employed in the historical and Representative Concentration Pathway (RCP) 8.5 experiments (Taylor et al., 2011; Vuuren et al., 2011; see Table S1 in Supplementary Material for an inventory of the models used). The increase in moist enthalpy between the end of the $20^{\text {th }}(1986-2005)$ and $21^{\text {st }}$ (2081-2100) centuries is greatest in extreme northern latitudes, but the change seen in the deep tropics comes a close second. Maximum increases in moist enthalpy at these latitudes are a consequence of the strong climate change feedbacks operating here, with reductions in surface albedo being of prime importance in the Arctic (Taylor et al., 2013), and the water vapour feedback acting at low latitudes (Colman 
and McAvaney, 2009). The increase in moist enthalpy is realised more though sensible (latent) heat in the high (low) latitudes (Fig. 5, bottom). It is this enhanced latent heating of the low latitude atmosphere that shallows the lapse rate and leads to the well-known strong sensible heating of the upper tropical atmosphere (Allen and Sherwood, 2008). At the surface, however, this increase in latent heat means that the rise in temperature is limited, which can obscure the fact that changes to moist enthalpy (and hence to potential heat stress: Section II) are so large.

The extent to which the changes in means shown in Fig. 5 extend to changes in extremes appears less straightforward and is underexplored. Zhao et al. (2015) reported near meridional-homogeneity in the amount that extremes (defined as the mean of the top 5\% of values) in heat-humidity indices (AT, SWBGT and HD) may rise by the end of the century under RCP 8.5. From Fig 5. this implies a relatively greater amplification of extremes in the mid-latitudes, which is in line with assessments of projected air temperature change that have indicted widening of statistical distributions there as the climate warms (Schär et al., 2004; Scherrer et al., 2005). From a process perspective, this may be explained by the dynamics of extreme mid-latitude heat events, where the role of land-atmosphere coupling under extratropical anticyclones in amplifying boundary-layer heat content has been highlighted (Miralles et al., 2014). Whilst not directly comparable with (Zhao et al., 2015), due to differences in definition of AT and spatial sampling, Matthews et al. (2017) noted that the 99.9th ${ }^{\text {th }}$ percentile in AT increased more in megacity locations with higher observed values for the $99.9^{\text {th }}$ percentile, suggesting that extremes in this indicator are amplified more under climate warming in the lower latitudes (Section II).

Although little research has assessed the amount that extreme values in heat-humidity indices may rise as the climate warms, there has been greater focus on the frequency with which potentially dangerous thresholds may be exceeded (Diffenbaugh et al., 2007; Fischer et al., 2012; Fischer and Schär, 2010; Matthews et al., 2017; Mora et al., 2017; Willett and Sherwood, 2012; Zhao et al., 2015). The results of these investigations indicate that it is the tropics and subtropics, where high heat stress is already encountered, that will generally witness the largest increases in the frequency of the most severe conditions. This trend can be understood as being a result of the climatological distribution of heat-humidity indices in the lower latitudes, where a high proportion of time is already spent in close proximity to critical thresholds. Thus, even a small increase in the mean can cause a relatively large increase in the frequency with which critical thresholds are crossed (Fischer et al., 2012; Mora et al., 2017b; Willett and Sherwood, 2012). Moreover, changes in the mean state of humidity-heat indices are likely to be amongst the largest in lower latitudes, adding to the tendency for the frequency of threshold exceedances to increase most there.

\section{Impacts}

The potential impacts of extreme heat in general have been thoroughly addressed in the literature (Sheridan and Allen, 2015). Here, focus is directed to those issues that become particularly notable when a humid-heat perspective is adopted. In this context, Section II outlined that, in the present climate, heat dissipation by humans to the environment is possible for almost all land areas on Earth. Assessments of heat-humidity indices have highlighted, however, that this may no longer be true under sustained climate warming, with wet bulb temperatures exceeding $35^{\circ} \mathrm{C}$ projected for parts of the Middle East and South Asia by the end of the century under RCP 8.5 (Im et al., 2017; Pal and Eltahir, 2016). These 
findings emphasise that there is an adaptability limit for humans in the context of climate change and heat stress, but it is important to note that negative health consequences are possible for wet bulb temperatures much lower than $35^{\circ} \mathrm{C}$, which is reflected in the advisory levels of heat-humidity indices (Table 1). Some authors have therefore attempted to quantify the number of people that may be exposed regularly to dangerous combinations of temperature and humidity if the climate continues to warm. For example, Im et al. (2017) found that by 2100 under RCP 8.5 around 4\% of South Asia's population may be exposed annually to wet bulb air temperatures exceeding the $35^{\circ} \mathrm{C}$ threshold, but up to $75 \%$ of people may be exposed to values dangerous to human health. In possibly the most comprehensive assessment to date, Mora et al. (2017) assessed 783 incidents of mortality documented in the research literature to identify heat-humidity conditions that have been deadly in the past (see Fig. 1). They concluded that around $30 \%$ of the current population is already regularly exposed to deadly heat (experiencing at least 20 days per year), with this figure climbing as high as $74 \%$ by the end of the century under RCP 8.5. Even if the most ambitions climate change mitigation targets are met (a scenario consistent with RCP 2.6), Mora et al. (2017) caution that $48 \%$ of the world's population could be at risk by 2100 .

Matthews et al. (2017) framed their impacts projections differently, referring to amounts of climate warming, rather than RCPs, to communicate the potential societal consequences from increasing humid heat. Using exceedances of $40.6^{\circ} \mathrm{C}$ in the National Weather Service's formulation of AT (Rothfusz, 1990), they found that, by 2050, even if global warming was limited to $1.5^{\circ} \mathrm{C}$ above pre-industrial levels, more than 350 million extra people living in the world's largest cities could be regularly exposed (experiencing at least 1 day per year) to deadly conditions.

Such steep increases in the number of people exposed to deadly heat result from some unfortunate coincidences. First, as noted by Jendritzky and Tinz (2009), places already heat stressed tend to have higher population densities, and extreme thresholds may be passed more readily for little warming in such climates (Section IV). Second, population growth over the rest of the $21^{\text {st }}$ Century is projected to be fastest in the lower latitudes, spatially coincident with the greatest increase in potential heat stress (Fig. 6).

Beyond challenges to human health, research has assessed the potential impacts on economic productivity, making use of the fact that clear guidelines exist for moderating physical work depending on values of the WBGT (Parsons, 2006). For example, using projections from the HadCM3 climate model, Kjellström et al. (2009) concluded that under the A2 climate scenario, peak reductions in labour capacity could reach $27 \%$ by the 2080 s, with the biggest losses occurring in Southeast Asia, Central and Southern America, and the Caribbean. In a globally-aggregated study, Dunne et al. (2013) used projections from the ESM2M model under RCP 8.5 to suggest that population-weighted labour production could decrease by almost $40 \%$ in the hottest months by 2100 , and by more than $60 \%$ by 2200 .

\section{Synthesis and Future Outlook}

Research from observations and projections indicate concurrent increases in sensible (from increasing air temperature) and latent (through rising humidity) heat in response to anthropogenic greenhouse gas forcing of the climate. This drives greater increases in moist enthalpy and potential heat stress than may be inferred from rising temperatures alone, underlining the importance of integrating humidity changes into heat-related climate impacts assessments. 
Studies adopting this perspective have shown the largest increase in the frequency of dangerous conditions should generally be expected in lower latitude climates already experiencing a high proportion of time proximate to critical thresholds. This largely concurs with temperature-only studies, which find the greatest increase in the frequency of extremes in the tropics (Harrington et al., 2016; Herold et al., 2017). However, important differences emerge when the role of rising humidity is acknowledged. Heat-humidity indices indicate that more frequent tropical extremes are likely to be accompanied by amongst the largest increase in mean values seen worldwide. Thus, in terms of humid-heat, it is not just the signal (change) to noise (natural variability) ratio which is amplified in the tropics, but the absolute change itself. There is not yet a clear consensus as to whether this tropical amplification applies equally to the warm tail. Exploring this in more detail should be a priority for future research, as there is a need to quantify changes to the intensity (rather than just the frequency) of heat extremes under sustained climate warming. Enhancing understanding of the physical processes driving extreme low-latitude heat-humidity events may be a valuable contribution in this regard.

The increasing risk of extreme heat-humidity in the low latitudes is in general spatially coincident with the largest rise in vulnerability due to rapid population growth. Accordingly, research has identified that continued climate change could lead to hundreds of millions more people regularly exposed to deadly heat, even if ambitious mitigation strategies succeed. It is possible that human populations may acclimatize somewhat in response to the more frequent stress from extreme temperatures, but scope for this is limited. First, optimum core body temperature should be regarded as immutable because basic components of human physiology (e.g. proteins) are highly temperature sensitive (Somero, 2010). Thus, $T_{W}=35^{\circ} \mathrm{C}$ should be considered a hard and absolute upper limit for human heat tolerance that will not change over the (decadal to centennial) timescales considered here. Second, whilst individuals' ability to cope with heat below this threshold may improve with increased thermoregulatory efficiency (for example, through earlier onset of sweating), it will still encounter limits set by human physiology (for example, maximal sweat rates) (Hanna and Tait, 2015).

Mindful of the limits to human acclimatization, there is a strong incentive to limit exposure to dangerous heat where possible. Because heat stress is a phenomena that has been, and will continue to be, experienced mainly in cities (Fischer et al., 2012), there is much scope to achieve this through physical modification of urban environments (Ahmadi Venhari et al., 2017; Taleghani, 2017). However, it is critical that studies exploring this prospect do so using heat-humidity indicators in place of air temperature; 'greening' cities through the introduction of more vegetation may well reduce the latter, but its influence on the former is unclear (Hass et al., 2016).

Alternatively, Heat Health Early Warning Systems (Lowe et al., 2011) generally aim to elicit behavioural changes that minimize impacts from extreme heat. To date, their implementation has been restricted mainly to Europe and North America (Boeckmann and Rohn, 2014), so there is much scope for their wider use across the most at-risk low latitudes (Knowlton et al., 2014). In this context, though, economic barriers must be acknowledged due to the generally reduced adaptive capacity of developing (often low latitude) countries. For example, cost may limit access to private air conditioning (see Gronlund, 2014), whilst lower-income workers may not feel able to afford avoiding strenuous work during periods of dangerous heat (Das, 2015). Addressing the growing challenge of deadly heat therefore requires 
innovations that simultaneously respect humans' physiological limits, yet remain practical for widespread deployment.

In closing, it is reiterated that integrating humidity into climate change assessments provides more complete insight into evolving thermal stress than provided by air temperature alone, but it must be acknowledged that, on their own, these variables incompletely characterise the outdoor environment for the purposes of human heat exchange. Wind speed and insolation are also critical in this regard, and both are projected to change as the climate warms (Ma et al., 2016; Wild et al., 2015). Going forward, trends in these quantities should therefore be assessed for better understanding of heat stress and climate change, not least for the outdoor workers who can comprise a large fraction of the workforce in vulnerable low latitudes regions.

\section{Funding}

This research received no specific grant from any funding agency in the public, commercial, or not-for-profit sectors

\section{References}

ACSM, 1984. Prevention of thermal injuries during distance running. Position stand.

American College of Sports Medicine. Med. J. Aust. 141, 876-879.

Ahmadi Venhari, A., Tenpierik, M.J., Mahdizadeh Hakak, A., 2017. Heat mitigation by greening the cities, a review study. Environ. Earth Ecol. 1. https://doi.org/10.24051/eee/67281

Allen, R.J., Sherwood, S.C., 2008. Warming maximum in the tropical upper troposphere deduced from thermal winds. Nat. Geosci. 1, 399-403. https://doi.org/10.1038/ngeo208

Blazejczyk, K., Epstein, Y., Jendritzky, G., Staiger, H., Tinz, B., 2012. Comparison of UTCI to selected thermal indices. Int. J. Biometeorol. 56, 515-535. https://doi.org/10.1007/s00484-011-0453-2

Boeckmann, M., Rohn, I., 2014. Is planned adaptation to heat reducing heat-related mortality and illness? A systematic review. BMC Public Health 14, 1112. https://doi.org/10.1186/1471-2458-14-1112

Bröde, P., Fiala, D., Błażejczyk, K., Holmér, I., Jendritzky, G., Kampmann, B., Tinz, B., Havenith, G., 2012. Deriving the operational procedure for the Universal Thermal Climate Index (UTCI). Int. J. Biometeorol. 56, 481-494. https://doi.org/10.1007/s00484-011-0454-1

Buzan, J.R., Oleson, K., Huber, M., 2015. Implementation and comparison of a suite of heat stress metrics within the Community Land Model version 4.5. Geosci. Model Dev. 8, 151-170. https://doi.org/10.5194/gmd-8-151-2015

Byrne, M.P., O’Gorman, P.A., 2016. Understanding Decreases in Land Relative Humidity with Global Warming: Conceptual Model and GCM Simulations. J. Clim. 29, 90459061. https://doi.org/10.1175/JCLI-D-16-0351.1

Byrne, M.P., O’Gorman, P.A., 2013. Link between land-ocean warming contrast and surface relative humidities in simulations with coupled climate models. Geophys. Res. Lett. 40, 5223-5227. https://doi.org/10.1002/grl.50971

Collins, M., Knutti, R., Arblaster, J., Dufresne, J.-L., Fichefet, T., Friedlingstein, P., Gao, X., Gutowski, W.., Johns, T., Krinner, G., Shongwe, M., Tebaldi, C., Weaver, A.J., Wehner, M., 2013. Long-term Climate Change: Projections, Commitments and 
Irreversibility., in: Climate Change 2013: The Physical Science Basis. Contribution of Working Group I to the Fifth Assessment Report of the Intergovernmental Panel on Climate Change. Cambridge University Press, Cambridge, United Kingdom and New York, NY USA.

Colman, R., McAvaney, B., 2009. Climate feedbacks under a very broad range of forcing. Geophys. Res. Lett. 36, L01702. https://doi.org/10.1029/2008GL036268

Dai, A., 2006. Recent Climatology, Variability, and Trends in Global Surface Humidity. J. Clim. 19, 3589-3606. https://doi.org/10.1175/JCLI3816.1

Das, S., 2015. Temperature increase, labor supply and cost of adaptation in developing economies: evidence on urban workers in informal sectors. Clim. Change Econ. 06, 1550007. https://doi.org/10.1142/S2010007815500074

Davis, R.E., McGregor, G.R., Enfield, K.B., 2016. Humidity: A review and primer on atmospheric moisture and human health. Environ. Res. 144, 106-116. https://doi.org/10.1016/j.envres.2015.10.014

Delworth, T.L., Mahlman, J.D., Knutson, T.R., 1999. Changes in Heat Index Associated with CO2-Induced Global Warming. Clim. Change 43, 369-386. https://doi.org/10.1023/A:1005463917086

Desai, M.S., Dhorde, A.G., 2017. Trends in thermal discomfort indices over western coastal cities of India. Theor. Appl. Climatol. 1-17. https://doi.org/10.1007/s00704-0172042-8

Diffenbaugh, N.S., Field, C.B., 2013. Changes in Ecologically Critical Terrestrial Climate Conditions. Science 341, 486-492. https://doi.org/10.1126/science.1237123

Diffenbaugh, N.S., Pal, J.S., Giorgi, F., Gao, X., 2007. Heat stress intensification in the Mediterranean climate change hotspot. Geophys. Res. Lett. 34, L11706. https://doi.org/10.1029/2007GL030000

Dunne, J.P., Stouffer, R.J., John, J.G., 2013. Reductions in labour capacity from heat stress under climate warming. Nat. Clim. Change 3, 563-566. https://doi.org/10.1038/nclimate1827

Fall, S., Diffenbaugh, N.S., Niyogi, D., Pielke, R.A., Rochon, G., 2010. Temperature and equivalent temperature over the United States (1979-2005). Int. J. Climatol. 30, 2045-2054. https://doi.org/10.1002/joc.2094

Fiala, D., Havenith, G., Bröde, P., Kampmann, B., Jendritzky, G., 2012. UTCI-Fiala multinode model of human heat transfer and temperature regulation. Int. J. Biometeorol. 56, 429-441. https://doi.org/10.1007/s00484-011-0424-7

Fischer, E.M., 2014. Climate science: Autopsy of two mega-heatwaves. Nat. Geosci. 7, 332333. https://doi.org/10.1038/ngeo2148

Fischer, E.M., Knutti, R., 2015. Anthropogenic contribution to global occurrence of heavyprecipitation and high-temperature extremes. Nat. Clim. Change 5, 560-564. https://doi.org/10.1038/nclimate2617

Fischer, E.M., Knutti, R., 2013. Robust projections of combined humidity and temperature extremes. Nat. Clim. Change 3, 126-130. https://doi.org/10.1038/nclimate1682

Fischer, E.M., Oleson, K.W., Lawrence, D.M., 2012. Contrasting urban and rural heat stress responses to climate change. Geophys. Res. Lett. 39, L03705. https://doi.org/10.1029/2011GL050576

Fischer, E.M., Schär, C., 2010. Consistent geographical patterns of changes in high-impact European heatwaves. Nat. Geosci. 3, 398-403.

Gagge, A.P., Gonzalez, R.R., 2010. Mechanisms of Heat Exchange: Biophysics and Physiology, in: Comprehensive Physiology. John Wiley \& Sons, Inc. https://doi.org/10.1002/cphy.cp040104 
Gronlund, C.J., 2014. Racial and socioeconomic disparities in heat-related health effects and their mechanisms: a review. Curr. Epidemiol. Rep. 1, 165-173. https://doi.org/10.1007/s40471-014-0014-4

Grundstein, A., Dowd, J., 2011. Trends in Extreme Apparent Temperatures over the United States, 1949-2010. J. Appl. Meteorol. Climatol. 50, 1650-1653. https://doi.org/10.1175/JAMC-D-11-063.1

Hajat, S., Kosatky, T., 2010. Heat-related mortality: a review and exploration of heterogeneity. J. Epidemiol. Community Health 64, 753-760. https://doi.org/10.1136/jech.2009.087999

Hanna, E.G., Tait, P.W., 2015. Limitations to Thermoregulation and Acclimatization Challenge Human Adaptation to Global Warming. Int. J. Environ. Res. Public. Health 12, 8034-8074. https://doi.org/10.3390/ijerph120708034

Harrington, L.J., Frame, D.J., Fischer, E.M., Hawkins, E., Joshi, M., Jones, C.D., 2016. Poorest countries experience earlier anthropogenic emergence of daily temperature extremes. Environ. Res. Lett. 11, 055007. https://doi.org/10.1088/17489326/11/5/055007

Hass, A.L., Ellis, K.N., Reyes Mason, L., Hathaway, J.M., Howe, D.A., 2016. Heat and Humidity in the City: Neighborhood Heat Index Variability in a Mid-Sized City in the Southeastern United States. Int. J. Environ. Res. Public. Health 13, 117. https://doi.org/10.3390/ijerph13010117

Held, I.M., Soden, and B.J., 2000. Water Vapor Feedback and Global Warming. Annu. Rev. Energy Environ. 25, 441-475. https://doi.org/10.1146/annurev.energy.25.1.441

Henderson-Sellers, B., 1984. A new formula for latent heat of vaporization of water as a function of temperature. Q. J. R. Meteorol. Soc. 110, 1186-1190. https://doi.org/10.1002/qj.49711046626

Herold, N., Alexander, L., Green, D., Donat, M., 2017. Greater increases in temperature extremes in low versus high income countries. Environ. Res. Lett. 12, 034007. https://doi.org/10.1088/1748-9326/aa5c43

Horton, R.M., Mankin, J.S., Lesk, C., Coffel, E., Raymond, C., 2016. A Review of Recent Advances in Research on Extreme Heat Events. Curr. Clim. Change Rep. 2, 242-259. https://doi.org/10.1007/s40641-016-0042-x

Hyatt, O.M., Lemke, B., Kjellstrom, T., 2010. Regional maps of occupational heat exposure: past, present, and potential future. Glob. Health Action 3, 5715. https://doi.org/10.3402/gha.v3i0.5715

Im, E.-S., Pal, J.S., Eltahir, E.A.B., 2017. Deadly heat waves projected in the densely populated agricultural regions of South Asia. Sci. Adv. 3, e1603322. https://doi.org/10.1126/sciadv.1603322

Jendritzky, G., Tinz, B., 2009. The thermal environment of the human being on the global scale. Glob. Health Action 2, 2005. https://doi.org/10.3402/gha.v2i0.2005

Jones, B., O’Neill, B.C., 2016. Spatially explicit global population scenarios consistent with the Shared Socioeconomic Pathways. Environ. Res. Lett. 11, 084003. https://doi.org/10.1088/1748-9326/11/8/084003

Joshi, M., Gregory, J., 2008. Dependence of the land-sea contrast in surface climate response on the nature of the forcing. Geophys. Res. Lett. 35, L24802. https://doi.org/10.1029/2008GL036234

Kántor, N., Unger, J., 2011. The most problematic variable in the course of humanbiometeorological comfort assessment - the mean radiant temperature. Cent. Eur. J. Geosci. 3, 90-100. https://doi.org/10.2478/s13533-011-0010-x

Kjellstrom, T., Briggs, D., Freyberg, C., Lemke, B., Otto, M., Hyatt, O., 2016. Heat, Human Performance, and Occupational Health: A Key Issue for the Assessment of Global 
Climate Change Impacts. Annu. Rev. Public Health 37, 97-112.

https://doi.org/10.1146/annurev-publhealth-032315-021740

Kjellstrom, T., Kovats, R.S., Lloyd, S.J., Holt, T., Tol, R.S.J., 2009. The direct impact of climate change on regional labor productivity. Arch. Environ. Occup. Health 64, $217-$ 227. https://doi.org/10.1080/19338240903352776

Kjellstrom, T., Lemke, B., Otto, M., 2013. Mapping occupational heat exposure and effects in South-East Asia: ongoing time trends 1980-2011 and future estimates to 2050. Ind. Health 51, 56-67.

Knowlton, K., Kulkarni, S.P., Azhar, G.S., Mavalankar, D., Jaiswal, A., Connolly, M., NoriSarma, A., Rajiva, A., Dutta, P., Deol, B., Sanchez, L., Khosla, R., Webster, P.J., Toma, V.E., Sheffield, P., Hess, J.J., the Ahmedabad Heat and Climate Study Group, 2014. Development and Implementation of South Asia's First Heat-Health Action Plan in Ahmedabad (Gujarat, India). Int. J. Environ. Res. Public. Health 11, 34733492. https://doi.org/10.3390/ijerph110403473

Lowe, D., Ebi, K.L., Forsberg, B., 2011. Heatwave Early Warning Systems and Adaptation Advice to Reduce Human Health Consequences of Heatwaves. Int. J. Environ. Res. Public. Health 8, 4623-4648. https://doi.org/10.3390/ijerph8124623

Ma, J., Foltz, G.R., Soden, B.J., Huang, G., He, J., Dong, C., 2016. Will surface winds weaken in response to global warming? Environ. Res. Lett. 11, 124012. https://doi.org/10.1088/1748-9326/11/12/124012

Masterton, J., Richardson, F., 1979. A method of quantifying human discomfort due to excessive heat and humidity. Environment Canada, Downside, Ontario.

Matthews, T.K.R., Wilby, R.L., Murphy, C., 2017. Communicating the deadly consequences of global warming for human heat stress. Proc. Natl. Acad. Sci. 114, 3861-3866. https://doi.org/10.1073/pnas.1617526114

Mekis, É., Vincent, L.A., Shephard, M.W., Zhang, X., 2015. Observed Trends in Severe Weather Conditions Based on Humidex, Wind Chill, and Heavy Rainfall Events in Canada for 1953-2012. Atmosphere-Ocean 53, 383-397. https://doi.org/10.1080/07055900.2015.1086970

Miralles, D.G., Teuling, A.J., van Heerwaarden, C.C., Vilà-Guerau de Arellano, J., 2014. Mega-heatwave temperatures due to combined soil desiccation and atmospheric heat accumulation. Nat. Geosci. 7, 345-349. https://doi.org/10.1038/ngeo2141

Mora, C., Counsell, C.W.W., Bielecki, C.R., Louis, L.V., 2017a. Twenty-Seven Ways a Heat Wave Can Kill You:: Deadly Heat in the Era of Climate Change. Circ. Cardiovasc. Qual. Outcomes 10, e004233. https://doi.org/10.1161/CIRCOUTCOMES.117.004233

Mora, C., Dousset, B., Caldwell, I.R., Powell, F.E., Geronimo, R.C., Bielecki, C.R., Counsell, C.W.W., Dietrich, B.S., Johnston, E.T., Louis, L.V., Lucas, M.P., McKenzie, M.M., Shea, A.G., Tseng, H., Giambelluca, T.W., Leon, L.R., Hawkins, E., Trauernicht, C., 2017b. Global risk of deadly heat. Nat. Clim. Change 7, 501-506. https://doi.org/10.1038/nclimate3322

Oke, T.R., 2009. Boundary Layer Climates, Second. ed. Routledge.

Oleson, K.W., Monaghan, A., Wilhelmi, O., Barlage, M., Brunsell, N., Feddema, J., Hu, L., Steinhoff, D.F., 2015. Interactions between urbanization, heat stress, and climate change. Clim. Change 129, 525-541. https://doi.org/10.1007/s10584-013-0936-8

Pal, J.S., Eltahir, E.A.B., 2016. Future temperature in southwest Asia projected to exceed a threshold for human adaptability. Nat. Clim. Change 6, 197-200. https://doi.org/10.1038/nclimate2833

Parsons, K., 2006. Heat Stress Standard ISO 7243 and its Global Application. Ind. Health 44, 368-379. https://doi.org/10.2486/indhealth.44.368 
Peterson, T.C., Willett, K.M., Thorne, P.W., 2011. Observed changes in surface atmospheric energy over land. Geophys. Res. Lett. 38, L16707. https://doi.org/10.1029/2011GL048442

Pielke, R.A., Davey, C., Morgan, J., 2004. Assessing “global warming” with surface heat content. Eos Trans. Am. Geophys. Union 85, 210-211. https://doi.org/10.1029/2004EO210004

Roghanchi, P., Kocsis, K.C., 2017. Challenges in Selecting an Appropriate Heat Stress Index to Protect Workers in Hot and Humid Underground Mines. Saf. Health Work. https://doi.org/10.1016/j.shaw.2017.04.002

Rothfusz, L.P., 1990. The heat index equation (or, more than you ever wanted to know about heat index) (Technical Attachment No. SR 90-23). National Oceanic and Atmospheric Administration, National Weather Service, Office of Meteorology.

Schär, C., Vidale, P.L., Lüthi, D., Frei, C., Häberli, C., Liniger, M.A., Appenzeller, C., 2004. The role of increasing temperature variability in European summer heatwaves. Nature 427, 332-336. https://doi.org/10.1038/nature02300

Scherrer, S.C., Appenzeller, C., Liniger, M.A., Schär, C., 2005. European temperature distribution changes in observations and climate change scenarios. Geophys. Res. Lett. 32, L19705. https://doi.org/10.1029/2005GL024108

Seneviratne, S.I., Donat, M.G., Mueller, B., Alexander, L.V., 2014. No pause in the increase of hot temperature extremes. Nat. Clim. Change 4, 161-163. https://doi.org/10.1038/nclimate2145

Sheridan, S.C., Allen, M.J., 2015. Changes in the Frequency and Intensity of Extreme Temperature Events and Human Health Concerns. Curr. Clim. Change Rep. 1, 155162. https://doi.org/10.1007/s40641-015-0017-3

Sherwood, S.C., Huber, M., 2010. An adaptability limit to climate change due to heat stress. Proc. Natl. Acad. Sci. 107, 9552-9555. https://doi.org/10.1073/pnas.0913352107

Sillmann, J., Kharin, V.V., Zwiers, F.W., Zhang, X., Bronaugh, D., 2013. Climate extremes indices in the CMIP5 multimodel ensemble: Part 2. Future climate projections. J. Geophys. Res. Atmospheres 118, 2473-2493. https://doi.org/10.1002/jgrd.50188

Simmons, A.J., Willett, K.M., Jones, P.D., Thorne, P.W., Dee, D.P., 2010. Low-frequency variations in surface atmospheric humidity, temperature, and precipitation: Inferences from reanalyses and monthly gridded observational data sets. J. Geophys. Res. Atmospheres 115, D01110. https://doi.org/10.1029/2009JD012442

Somero, G.N., 2010. The physiology of climate change: how potentials for acclimatization and genetic adaptation will determine "winners" and "losers.” J. Exp. Biol. 213, 912920. https://doi.org/10.1242/jeb.037473

Steadman, R.G., 1979. The Assessment of Sultriness. Part I: A Temperature-Humidity Index Based on Human Physiology and Clothing Science. J. Appl. Meteorol. 18, 861-873. https://doi.org/10.1175/1520-0450(1979)018<0861:TAOSPI>2.0.CO;2

Sutton, R.T., Dong, B., Gregory, J.M., 2007. Land/sea warming ratio in response to climate change: IPCC AR4 model results and comparison with observations. Geophys. Res. Lett. 34, L02701. https://doi.org/10.1029/2006GL028164

Taleghani, M., 2017. Outdoor thermal comfort by different heat mitigation strategies- A review. Renew. Sustain. Energy Rev. https://doi.org/10.1016/j.rser.2017.06.010

Taylor, K.E., Stouffer, R.J., Meehl, G.A., 2011. An Overview of CMIP5 and the Experiment Design. Bull. Am. Meteorol. Soc. 93, 485-498. https://doi.org/10.1175/BAMS-D-1100094.1

Taylor, P.C., Cai, M., Hu, A., Meehl, J., Washington, W., Zhang, G.J., 2013. A Decomposition of Feedback Contributions to Polar Warming Amplification. J. Clim. 26, 7023-7043. https://doi.org/10.1175/JCLI-D-12-00696.1 
Vuuren, D.P. van, Edmonds, J.A., Kainuma, M., Riahi, K., Weyant, J., 2011. A special issue on the RCPs. Clim. Change 109, 1. https://doi.org/10.1007/s10584-011-0157-y

Wehner, M., Stone, D., Krishnan, H., AchutaRao, K., Castillo, F., 2016. The Deadly Combination of Heat and Humidity in India and Pakistan in Summer 2015. Bull. Am. Meteorol. Soc. 97, S81-S86. https://doi.org/10.1175/BAMS-D-16-0145.1

Wild, M., Folini, D., Henschel, F., Fischer, N., Müller, B., 2015. Projections of long-term changes in solar radiation based on CMIP5 climate models and their influence on energy yields of photovoltaic systems. Sol. Energy 116, 12-24. https://doi.org/10.1016/j.solener.2015.03.039

Willett, K.M., Dunn, R.J.H., Thorne, P.W., Bell, S., de Podesta, M., Parker, D.E., Jones, P.D., Williams Jr., C.N., 2014. HadISDH land surface multi-variable humidity and temperature record for climate monitoring. Clim Past 10, 1983-2006. https://doi.org/10.5194/cp-10-1983-2014

Willett, K.M., Sherwood, S., 2012. Exceedance of heat index thresholds for 15 regions under a warming climate using the wet-bulb globe temperature. Int. J. Climatol. 32, 161177. https://doi.org/10.1002/joc.2257

Yaglou, C.P., Minard, D., 1957. Control of heat casualties at military training centers. AMA Arch. Ind. Health 16, 302-316.

Zhao, Y., Ducharne, A., Sultan, B., Braconnot, P., Vautard, R., 2015. Estimating heat stress from climate-based indicators: present-day biases and future spreads in the CMIP5 global climate model ensemble. Environ. Res. Lett. 10, 084013. https://doi.org/10.1088/1748-9326/10/8/084013

\section{Figure and Table Captions}

Figure 1. Enthalpy potential (the term in square brackets in Equation 4) expressed in ${ }^{\circ} \mathrm{C}$ for $\mathrm{LR}=16.5 \mathrm{~K} \mathrm{kPa}^{-1}$ (Gagge and Gonzalez, 2010). Negative values indicate cooling potential, as the gradient is directed from the skin to the environment. The hatched area highlights positive values; red line marks $T_{W}=35^{\circ} \mathrm{C}$. The orange line highlights temperature and humidity combinations for which heat dissipation to the environment is not possible using equations 1-3, with $\mathrm{q}_{\mathrm{s}}=0, \mathrm{q}_{\mathrm{G}}=0, \mathrm{hc}=5.8 \mathrm{~W} \mathrm{~m}^{-2} \mathrm{~K}^{-1}$ (appropriate for sea-level and ambient air velocity of $0.25 \mathrm{~m} \mathrm{~s}^{-1}$ :Gagge and Gonzalez, 2010), and $\mathrm{q}_{\mathrm{Lw}}$ determined from $\sigma \varepsilon_{A} T_{A}{ }^{4}-$ $\sigma \varepsilon_{S K} T_{S K}{ }^{4}$, with $\sigma$ the Stefan Boltzmann constant, and emissivity $(\varepsilon)$ of the surrounding surfaces (subscript $A$ ) and skin (SK) assigned values of 0.95 (Kántor and Unger, 2011) and 0.9 , respectively. The latter can be considered appropriate for an urban environment (Oke, 2009). For all calculations, $\mathrm{T}_{\mathrm{SK}}=35^{\circ} \mathrm{C}$. Dotted lines mainly indicate the onset of the "strong" heat stress class according to different heat-humidity indices (see Section II and Table 1). UTCI was computed with a $3.3 \mathrm{~m} \mathrm{~s}^{-1}$ wind, and mean radiant temperature equal to the air temperature). The "Mora et al. (2017b)" line highlights a global-scale empirically-derived threshold for identifying deadly heat (see Section V).

Figure 2. All time maximum 2-metre moist enthalpy (Q) at each grid point in the hourly ERA5 dataset, along with concurrent sensible $\left(\mathrm{Q}_{\mathrm{h}}\right)$ and latent $\left(\mathrm{Q}_{\mathrm{l}}\right)$ contributions. (D) is the bivariate distribution of $\mathrm{Q}$ and the ratio $\mathrm{Q}_{\mathrm{l}} / \mathrm{Q}_{\mathrm{h}}$, highlighting higher contributions of $\mathrm{Q}_{1}$ to $\mathrm{Q}$ as $\mathrm{Q}$ increases. The green points show the top-ten values, with the wet-bulb temperature of the highest value annotated. The red distribution and scatter points displays the same information, but for energy content during conditions associated with the all-time maxima in hourly air temperatures at each grid point.

Figure 3.Area-weighted histograms of maximum temperature at each grid point in the hourly ERA5 dataset. Densities of the 2010 population (Jones and O’Neill, 2016) are calculated as 
function of air temperature. The magenta line indicates the number of people to have experienced a (dry-bulb) air temperature at least as high as that indicated on the x-axis; the red, vertical line highlights the $35^{\circ} \mathrm{C}$ coordinate. Note that the $\mathrm{x}$-axis denotes wet- or dry-bulb temperature, depending on the units of the series plotted.

Figure 4. Common heat-humidity indices (dotted lines), compared to moist enthalpy (solid lines) as a function of air temperature and relative humidity. See text for abbreviations, and note that the UTCI was computed assuming a mean radiant temperature equal to air temperature, and a 10-metre wind speed of $3.3 \mathrm{~m} \mathrm{~s}^{-1}$. Note that the grey region corresponds to the hatched area in Fig. 1.

Figure 5. Top: ensemble mean change in mean moist enthalpy by the end of the century (2081-2100), relative to 1986-2005 according to RCP 8.5. Note that all model output were interpolated to a common $1^{\circ} \times 1^{\circ}$ grid for plotting. Bottom: zonal mean summary of the enthalpy change, with shading spanning \pm one standard deviation of the 23 CMIP5 ensemble members.

Figure 6. Zonal mean change in population and heat stress. Population changes are shown as the zonal-mean increases in population between 2050 and 2010, averaged across the Shared Socioeconomic Pathways (SSPs) provided by Jones and O’Neill (2016); shading spans \pm one standard deviation across these SSPs. Change in the frequency of dangerous AT is taken from (Matthews et al., 2017), and represents the zonal mean change in the number of days with AT $\geq 40.6^{\circ} \mathrm{C}$ in a climate $2^{\circ} \mathrm{C}$ warmer than preindustrial, relative to the climate of the recent past (1979-2005).

Table 1. Thresholds in commonly-employed heat-humidity indices. Note that these values are indices only but can be interpreted as having units of ${ }^{\circ} \mathrm{C}$ for comparative purposes. 


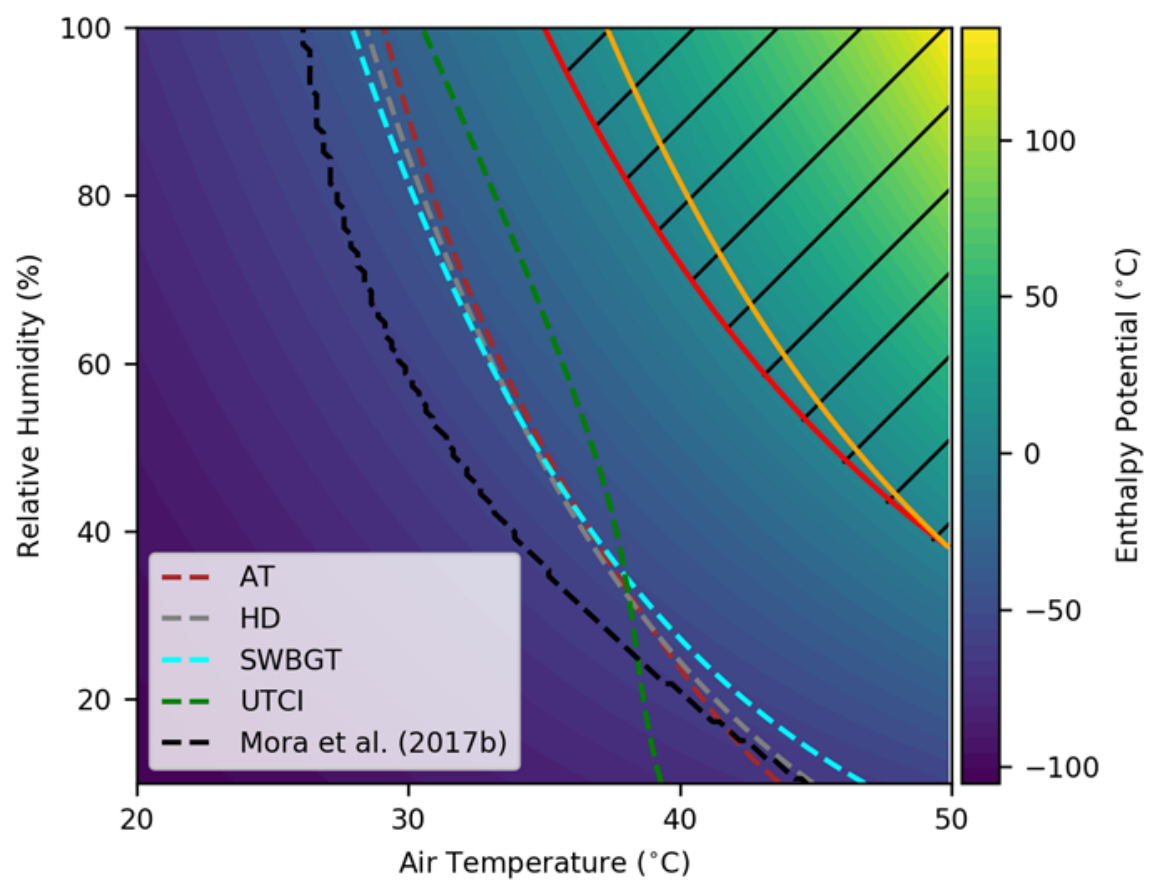



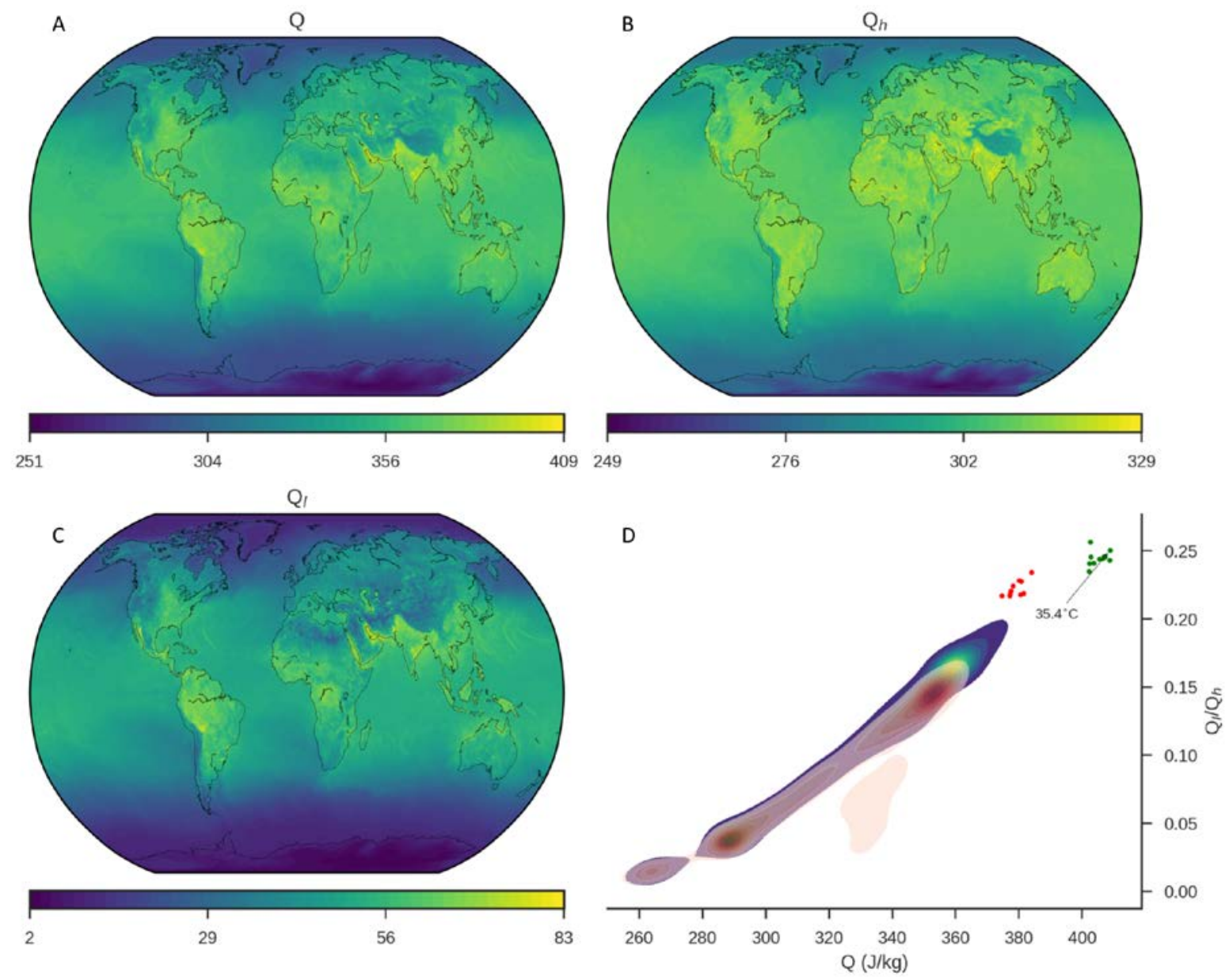


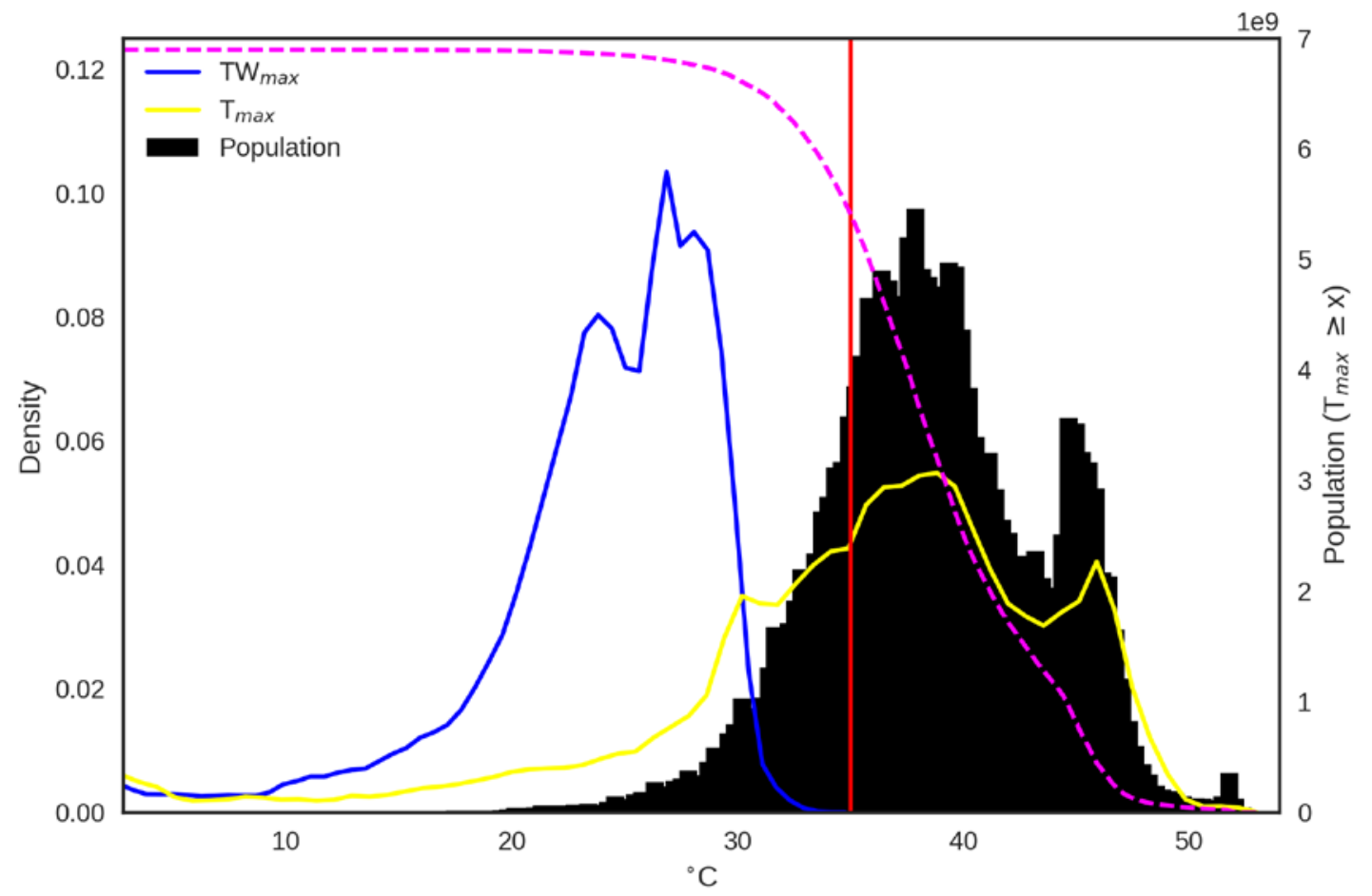




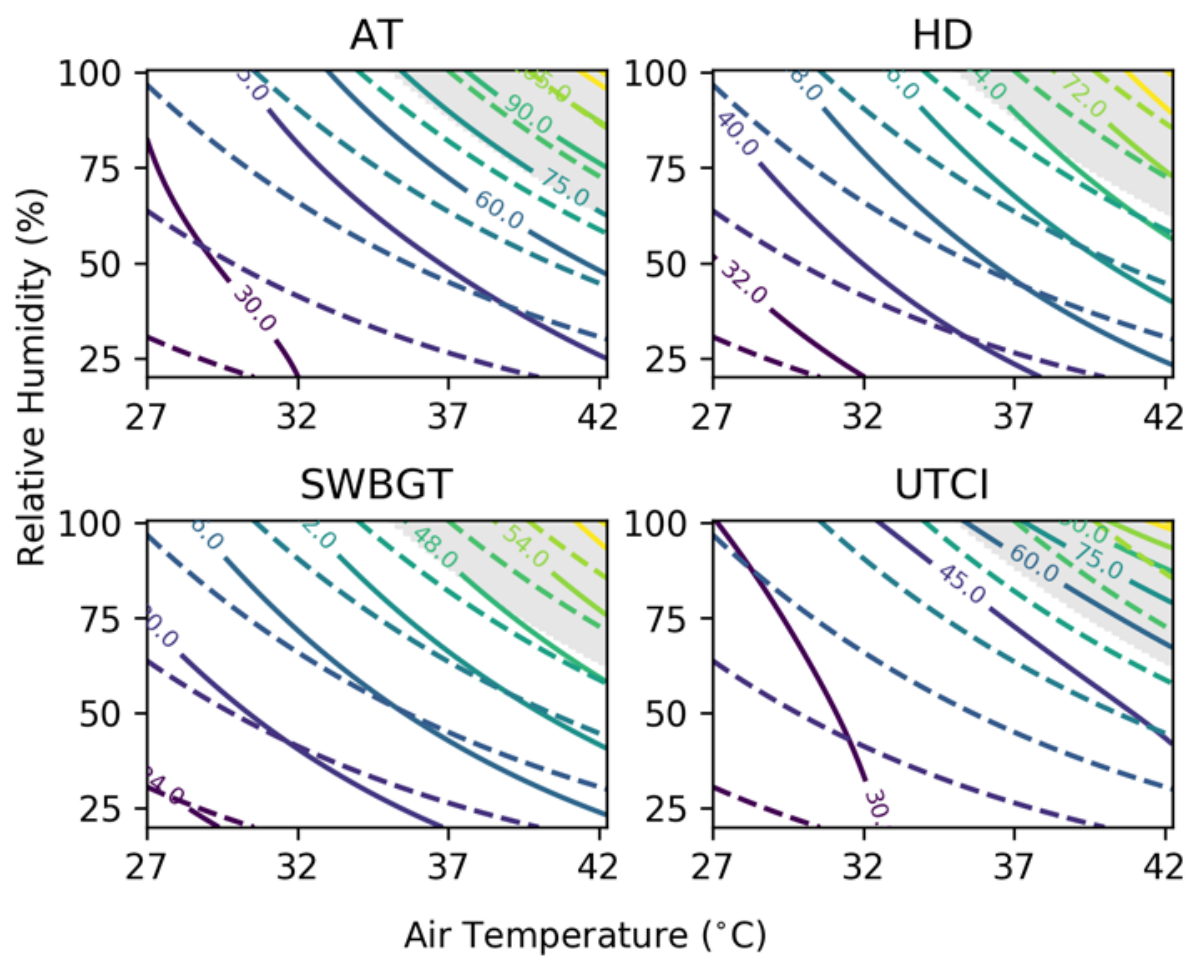



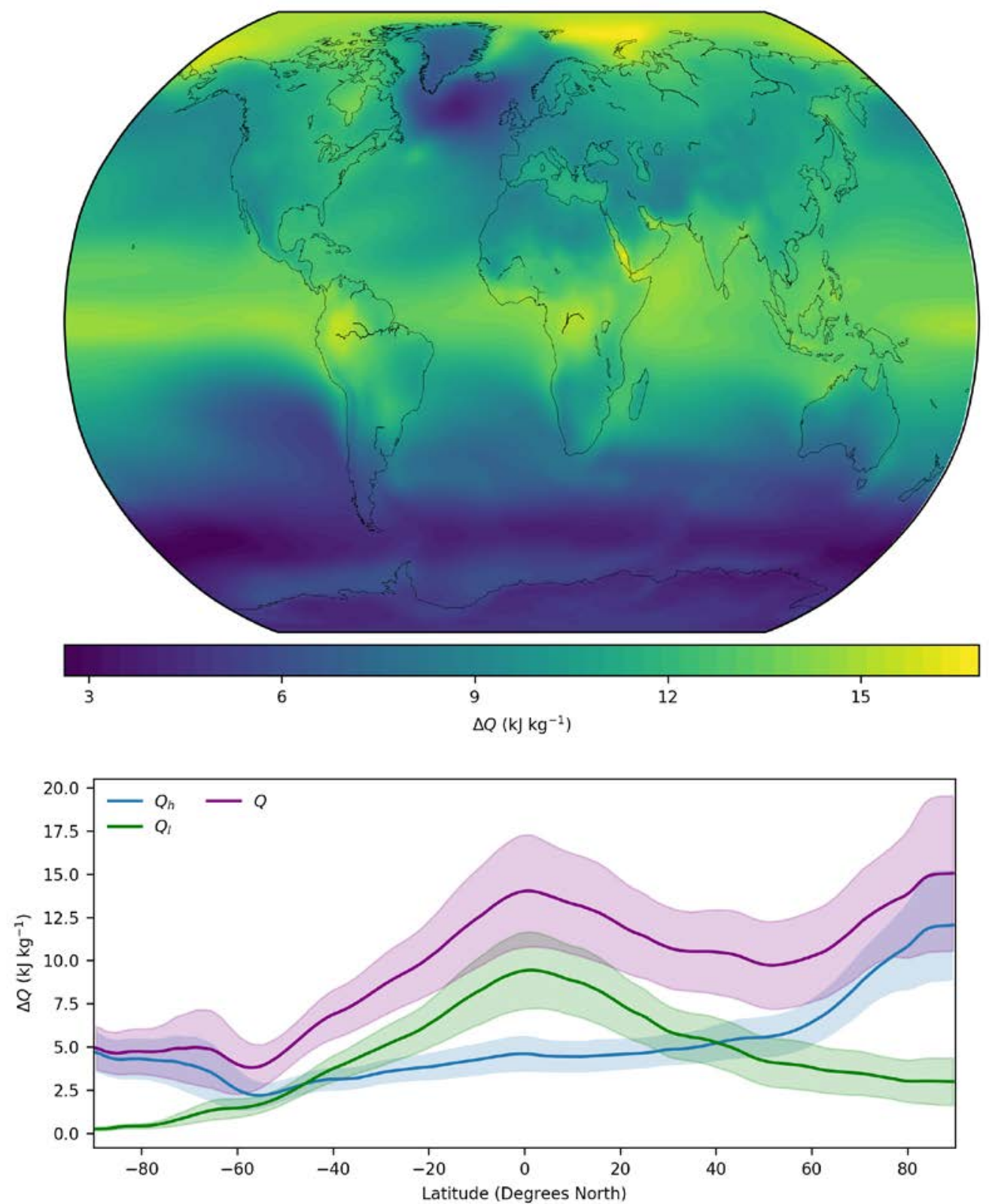


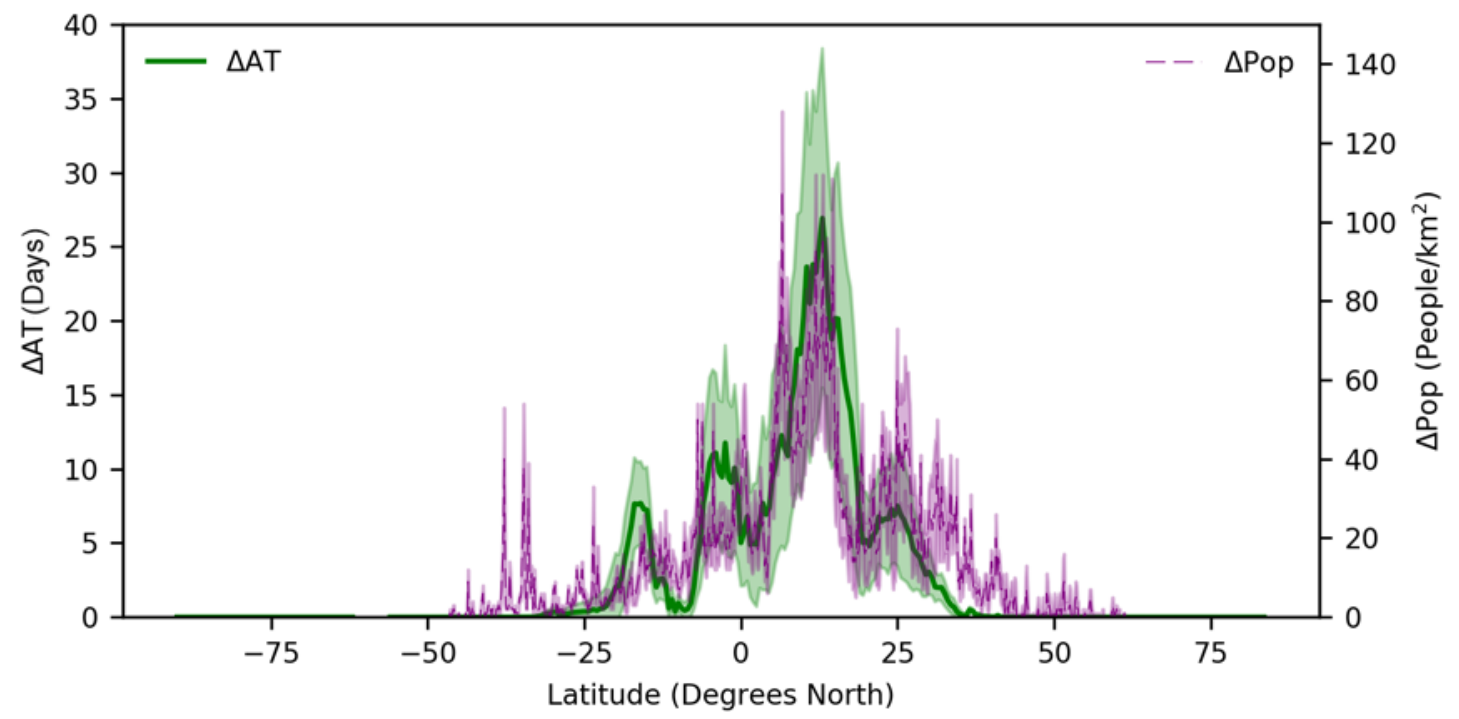

